\title{
A EDUCAÇÃO INFANTIL E O PLANO MUNICIPAL DE EDUCAÇÃO DO MUNICÍPIO DE MATÃO (SP): ATENDIMENTO À DEMANDA E INFRA- ESTRUTURA
}

Carlos da Fonseca BRANDÃO ${ }^{1}$

Fátima Gil de Oliveira TREVELIN ${ }^{2}$

Vitor Hugo PISSAIA ${ }^{3}$

RESUMO: Este artigo propõe-se a analisar o atendimento à demanda e as condições de infraestrutura dos prédios de educação infantil da rede municipal de ensino do município de Matão (SP) e comparar com as propostas para esse nível de ensino, nesses aspectos (oferta, atendimento e infraestrutura) presentes no Plano Municipal de Educação de Matão (PME 2003-2013). Ao final, esse trabalho faz algumas constatações sobre a situação atual desse sistema de ensino no nível da Educação Infantil, identificando que os seus problemas também são problemas presentes em uma grande quantidade de municípios brasileiros, especialmente o problema da demanda maior que a oferta de vagas na Educação Infantil, principalmente no que se refere às Creches.

PALAVRAS-CHAVE: Educação infantil. PME - Plano Municipal de Educação. Atendimento. Oferta. Infraestrutura.

\section{INTRODUÇÃO ${ }^{4}$}

A educação infantil brasileira, para alguns autores, é resultado de um processo histórico entre duas dimensões: uma social, política e administrativa e outra constituída por estudos da psicologia, antropologia, sociologia e filosofia que passam a conceber a criança como parte fundamental no processo de formação humana (KRAMER; NUNES; CORSINO, 2011).

No Brasil até o século XVIII não havia instituições coletivas de atendimento a criança pequena, a mortalidade infantil era tão elevada que no imaginário social bebês eram idealizados como anjos, para minimizar a repercussão dessas mortes (TRINDADE, 1999). Já o conceito de escola, segundo Boto (1996), só surgiu no século XIX, a partir da revolução burguesa.

A Constituição brasileira de 1988 pode ser considerada como o primeiro passo normativo-legal na direção da proposição da universalização do atendimento da

${ }^{1}$ UNESP - Universidade Estadual Paulista. Faculdade de Ciências e Letras de Assis - Departamento de Educação. Assis - SP - Brasil. 19806-900 - cbrandao@ assis.unesp.br

${ }^{2}$ Mestranda do Programa de Pós-graduação em Educação. UNESP - Universidade Estadual Paulista. Faculdade de Filosofia e Ciências. Marília - SP - Brasil. 17525-900 - fatiminha2008_@ hotmail.com

${ }^{3}$ Secretário Municipal de Educação do município de Cândido Rodrigues. Doutorando em Educação. UNESP - Universidade Estadual Paulista. Faculdade de Filosofia e Ciências - Pós-graduação em Educação. Marília - SP - Brasil. 17525-900 - vhpissaia@ hotmail.com

${ }^{4}$ Esse artigo é resultado parcial de pesquisa financiada pelo Edital no 07/2011 MCTI / CNPq / MEC / CAPES. 
Educação Infantil, responsabilizando o Estado por essa oferta (BRANDÃO, 2007). Porém, na década de 1990, com a hegemonia de governos de tendência neoliberal em boa parte da América Latina, incluindo o Brasil, a ideia de que a qualidade da educação estava diretamente relacionada com a melhoria da qualidade da gestão da educação, tornou-se predominante.

Para Tomé (2014), a proposta de uma nova gestão pública da educação, imposta pelo Estado aos estabelecimentos de educação, fundamentou-se, essencialmente, em uma perspectiva de cunho gerencial. Assim, as políticas públicas educacionais daquele momento, minimizavam o papel do Estado e, ao mesmo tempo, procuravam difundir a ideia de uma maior responsabilização da sociedade pela qualidade da educação pública.

Fazendo uma espécie de confronto entre as lógicas democrática e gerencial de gestão da escola pública no Brasil, Tomé (2014) afirma que as políticas educacionais públicas daquele momento, foram marcadas por um hibridismo entre essas duas lógicas, visto que, apesar de muito difundida pelos agentes do Estado, a lógica de gestão gerencial, com finalidade de minimizar o papel do Estado, não obteve a legitimidade perante a comunidade escolar.

De acordo com a Constituição Federal de 1988, com a Lei de Diretrizes e Bases da Educação Nacional (LDB - Lei n ${ }^{\circ}$ 9.394/96) e com o antigo Plano Nacional de Educação (PNE 2001-2011 - Lei n 10.172/01), a gestão democrática das escolas públicas deveria ser normatizada pelos sistemas municipais de ensino (BRASIL, 2006; BRANDÃO, 2004, 2006, 2010). O novo Plano Nacional de Educação (PNE 2014-2024 - Lei $\left.n^{\circ} 13.005 / 14\right)$, retoma essa questão em sua Meta $n^{\circ} 19$, propondo que, até 2016, estejam asseguradas as condições para a implantação efetiva da gestão democrática nas escolas públicas (BRANDÃO, 2014). Isso significa que, apesar da concepção de que a educação pública deve ter uma gestão democrática, ainda hoje não conseguimos efetivála.

Seguindo o raciocínio de Tomé (2014), a partir de 2007, foi possível constatar um hibridismo na lógica para a gestão da escola, pois ao mesmo tempo em que melhoraram as condições de financiamento, especialmente em função da implantação do FUNDEB (Fundo de Manutenção e Desenvolvimento da Educação Básica e de Valorização dos Profissionais de Educação - 2008), a lógica gerencial ainda estava presente nas políticas educacionais públicas de muitos Estados brasileiros.

No contexto da concepção da lógica gerencial da educação pública, os sistemas de ensino (estaduais e municipais) procuraram descentralizar a gestão da escola sob o 
discurso de promoção de autonomia, minimizando suas responsabilidades, porém, nunca abriram mão do gerenciamento dos recursos financeiros mais significativos.

Entretanto o padrão de gestão gerencial não é condizente com a prática educacional emancipatória, que travestido de um discurso de autonomia institucional promoveu a desresponsabilização do Estado com a educação pública de qualidade no Brasil, suas principais consequências foram:

[...] a despolitização dos profissionais da educação, o incentivo à pedagogia por projetos, à cultura de eficiência e demonstração de resultados individuais, a meritocracia, a precarização do trabalho dos educadores (salas superlotadas, falta de recursos materiais, aumento de atividades burocráticas sem pagamento para isso), a responsabilização unilateral dos professores pela qualidade da educação, a transformação da educação em mercadoria e a utilização do discurso científico e dos movimentos sociais em defesa da educação pública pelo Estado para justificar políticas educacionais anteriormente assumidas em acordos internacionais. (TOMÉ, 2014, p.76).

Assim, a educação foi parcialmente transformada em mercadoria, fundamentada em uma visão econômica e empresarial, onde as escolas precisam atingir metas quantitativas, baseadas nos resultados de avaliações de larga escala, que, em tese, objetivam demonstrar a qualidade da educação por meio de índices nacionais (IDEB) e/ou estaduais (INDESP, por exemplo, no estado de São Paulo). Porém esse conceito de qualidade é "complexo e envolve múltiplas dimensões" e a qualidade da educação "não poderia ser compreendida apenas a partir da definição de recursos materiais e humanos para a escola ou através do ranqueamento da aprendizagem dos estudantes". (DOURADO, 2007).

Diante desse quadro, e sob a justificativa de melhorar o desempenho dos alunos do primeiro ciclo do Ensino Fundamental (antigas $1^{\mathrm{a}}$ a $4^{\mathrm{a}}$ séries), é proposto e regulamentado o Ensino Fundamental com nove anos de duração ${ }^{5}$. Para Algebaile (2009), a principal motivação para essa ampliação do Ensino Fundamental foi muito mais econômica do que didática, pedagógica, cognitiva, psicossocial, etc. Para essa autora,

[...] a mesma reforma que estabelecia a responsabilidade dos municípios com a educação infantil criava um mecanismo de

${ }^{5}$ O Ensino Fundamental de nove anos, com matrícula obrigatória da criança com seis anos, foi implantado pela Lei $\mathrm{n}^{\circ} 11.274$, de 6 de fevereiro de 2006, o qual deveria ser implantado em todo território nacional até 2010 (BRANDÃO, 2009, p. 17). 
redistribuição financeira que favorecia os municípios com grande número de matrículas em ensino fundamental, desestimulando e mesmo impedindo, em alguns casos, a aplicação de recursos naquele nível de ensino. Por pressão da grande ampliação da demanda, vários municípios têm criado escolas de educação infantil como anexos de escolas de ensino fundamental, facilitando a transferência interna de recursos materiais e funcionais [...] (ALGEBAILE, 2009, p. 300).

De uma certa maneira, ao optar pela entrada da criança com 6 anos no Ensino Fundamental, ao invés de investir na Educação Infantil, essa etapa escolar assume um caráter assistencialista nas creches ( 0 a 3 anos) e de escolarização precoce nas préescolas (4 a 5 anos), segundo alguns autores (CAMPOS; FULGRAF; WIGGERS, 2006). Este estudo avaliou o atendimento em Educação Infantil nas seguintes variáveis: formação de professores, propostas pedagógicas, práticas educativas, relação da instituição com as famílias atendidas e condições de funcionamento.

Quanto à formação de professores, observou-se que a escolarização dos profissionais que atuam com crianças de zero até três anos era menor do que os que trabalhavam na pré-escola, e mesmo aqueles com magistério ou curso superior (Pedagogia), não tinham formação específica para o ensino infantil. Já monitores ou auxiliares de creches, não tinham nem mesmo formação em nível médio.

$\mathrm{Na}$ análise das propostas pedagógicas, muitas instituições não tinham projetos pedagógicos elaborados e quando tinham não consideravam a especificidade das idades das crianças, além de se constatar o predomínio de currículos que valorizavam mais o desenvolvimento cognitivo do que a formação integral da criança.

$\mathrm{O}$ aspecto do relacionamento com as famílias é descrito como conturbado, pois, enquanto os educadores acreditam que os pais só recorrem as creches por não ter onde deixar os filhos, estes, por sua vez, acham que a Educação Infantil deveria preparar seus filhos para o Ensino Fundamental. Essa pesquisa também constatou, segundo seus autores, um olhar preconceituoso por parte dos educadores, principalmente se a família é composta por mães solteiras ou pais desempregados, que foge ao padrão familiar do ideário social. A constatação desse tipo de preconceito mostra a necessidade de se investir, com mais qualidade, na formação dos educadores que trabalham nessa realidade (que é a realidade da imensa maioria das escolas públicas brasileiras).

Quanto ao papel desempenhado pelos diretores e coordenadores pedagógicos no planejamento das atividades anuais, essa pesquisa demonstrou que a participação desses profissionais de dava de maneira bem restrita, pois os mesmos recebiam o planejamento 
e calendário escolar prontos das suas respectivas secretarias municipais de educação e, apenas os cumpriam. Nos municípios estudados pela pesquisa desses autores, o mecanismo de nomeação para os cargos de direção de escola e de coordenação pedagógica era exclusivamente por indicação, e em apenas metade havia plano de carreira para os profissionais da Educação Infantil.

Para as condições de funcionamento e práticas educativas havia padrões incomuns, apesar das diferenças regionais no país. Exatamente por isso é que nossa pesquisa escolheu um município da região central do estado de São Paulo para analisar as condições oferta, atendimento e infraestrutura, relacionando tais condições com o Plano Municipal de Educação (2003-2013) do município de Matão (SP), análise essa que passamos a descrever em seguida.

\section{CARACTERÍSTICAS GERAIS DO MUNICÍPIO DE MATÃO.}

Distante $305 \mathrm{~km}$ da capital do estado de São Paulo, o município de Matão localiza-se na mesorregião de Araraquara, com aproximadamente 77 mil habitantes, com um crescimento de, aproximadamente $7 \%$ na primeira década do século XXI, segundo o Censo 2010 do IBGE (Fundação Instituto Brasileiro de Geografia e Estatística). Essencialmente urbano, a maioria de seus habitantes é do sexo feminino (aproximadamente 51\%).

Ainda segundo o IBGE, o município de Matão possui um total de 68 instituições escolares, divididas em 29 escolas de Ensino Fundamental, 25 de Educação Infantil e 14 de Ensino Médio. O total de alunos matriculados nas instituições escolares supera 15 mil matrículas, representando $20,3 \%$ do total de habitantes. Do total das matrículas, no Ensino Fundamental foram efetuadas 10.044 matrículas, sendo a grande maioria. A Educação Infantil teve 1.950 matrículas e o Ensino Médio teve, em 2010, 3.312 matrículas.

Do total de 25 escolas de Educação Infantil, 21 unidades escolares desse nível de ensino pertencem à rede municipal de ensino. Dessas unidades escolares, 16 escolas atendem alunos em idade de Creche ( 0 a 3 anos) e em idade pré-escolar (4 e 5 anos). Apenas 3 escolas atendem exclusivamente alunos em idade pré-escolar (4 e 5 anos) e apenas 2 escolas atendem somente alunos de Creche (0 a 3 anos). Além dessas escolas, outras creches atendem o excedente de crianças dessa faixa etária ( 0 a 3 anos), num total de quase 150 crianças, sendo ambas administradas pela Igreja Católica, com subsídios da Prefeitura Municipal. Assim, em 2013, o número absoluto de matrículas de alunos na 
Educação Infantil da rede municipal de ensino de Matão, foi de 2.847 alunos matriculados, sendo 1.598 alunos na pré-escola $(56,13 \%)$ e 1.249 crianças nas creches $(43,87 \%)$.

\section{OFERTA, ATENDIMENTO E INFRAESTRUTURA.}

No que se refere à questão do atendimento na Educação Infantil no município de Matão, considerando as unidades escolares com seu respectivo entorno e considerando, por um lado, a obrigatoriedade de matricular as crianças de 0 a 3 anos nas Creches e, por outro lado, a não obrigatoriedade de matricular crianças em período integral em Préescola, visto que a rede municipal de Matão atende, em período parcial, toda a demanda do município para a Pré-escola, podemos fazer três considerações iniciais.

A primeira consideração é que, do total de 21 unidades escolares que atendem a Educação Infantil da rede municipal de ensino, apenas 07 escolas $(33,33 \%)$ atendem sua demanda plenamente, incluindo o atendimento, dentro da mesma escola, para crianças de 0 a 3 anos (Creche dentro da unidade escolar) e crianças de 4 e 5 anos (Pré-escola). Assim, as outras 14 unidades escolares (66\% do total das unidades escolares) não atendem a demanda da Creche e a Pré-escola.

Uma segunda consideração a ser feita é que, do montante de 4.125 crianças em idade de Educação Infantil (0 a 5 anos), o município não atende aproximadamente $31 \%$ de sua demanda, ou seja, 1.278 crianças estão fora da escola da Educação Infantil no município de Matão. Se dividirmos a análise dessa questão especificamente para o nível das Creches e para o nível das Pré-escolas temos a seguinte situação: no nível das creches, de um total de 2.067 crianças de 0 a 3 no município de Matão, 818 crianças (aproximadamente, 40\%) estão fora das creches, sejam estas localizadas dentro ou fora das escolas municipais de Educação Infantil. Já no nível da Pré-escola, de um total de 2058 crianças de 4 e 5 anos do município de Matão, 460 crianças (aproximadamente, $22 \%$ ) estão fora da Pré-escola.

Uma última constatação a que essa pesquisa chegou é que foram as unidades escolares que, em quase a sua totalidade, atendem tanto a Creche como a Pré-escola, onde o problema do não atendimento da demanda esteve presente. Isso pode significar que são nos bairros onde estão localizadas as escolas de Educação Infantil, que, portanto, atendem simultaneamente, crianças de 0 a 3 anos (Creche) e 4 e 5 anos (Préescola) é onde se localiza uma parte mais significativa das crianças da faixa etária de 0 a 5 anos que estão fora do sistema escolar municipal. 
Em termos de infraestrutura física, avaliada pela própria Secretaria Municipal de Educação de Matão, foi constatado que a imensa maioria das escolas $(71,4 \%)$ mostrouse em condições ideais de infraestrutura e/ou em fase de acabamento de reformas/adequações. As escolas consideradas em condições de infraestrutura parcialmente ideais foram $23,8 \%$ e apenas uma unidade escolar da rede municipal de ensino mostrou-se em condições não ideais.

Considerando as 15 unidades escolares que atendem de forma ideal em termos de infraestrutura, 10 escolas $(66,6 \%)$ apresentaram alguma ressalva em relação à infraestrutura (por exemplo, condições ideais de acessibilidade), 4 unidades escolares $(26,6 \%)$ são consideradas plenamente ideais, ou seja, sem ressalva alguma em termos de infraestrutura e apenas uma escola $(6,8 \%)$ poderá vir a ser considerada ideal em termos de infraestrutura, assim que a reforma que nela está sendo realizada seja concluída. Das 8 unidades escolares que foram consideradas ideais com uma ressalva, a imensa maioria mencionou que apresentam problemas de acessibilidade.

Através das informações apontadas anteriormente referentes ao atendimento (número de unidades escolares, alunos matriculados e demanda não atendida) e às condições consideradas ideais ou não de infraestrutura física das unidades escolares de Educação Infantil da rede municipal de ensino de Matão, analisaremos, a seguir, o Plano Municipal de Educação (PME) de Matão, procurando enfatizar as questões centrais postas por essa pesquisa, quer sejam, a oferta, o atendimento e a infraestrutura das escolas de Educação Infantil do município de Matão (SP).

\section{O PLANO MUNICIPAL DE EDUCAÇÃO DE MATÃO (PME - 2003/2013).}

O Plano Municipal de Educação de Matão (PME - 2003/2013) foi instituído pela Lei $n^{\circ}$. 3.376, de 16 de dezembro de 2003 e, logo no primeiro parágrafo de seu texto, salienta a importância de atendimento à oferta e à demanda.

O Plano Municipal de Educação de Matão foi elaborado para ser o norteador da política educacional do município, procurando definir as prioridades de ação e as estratégias de atuação do Poder Público para um horizonte de dez anos. Para tanto, o plano parte de um diagnóstico da situação do município, tanto do ponto de vista da análise dos dados estatísticos sobre a evolução e as tendências da oferta e da demanda de ensino, quanto da identificação das necessidades educacionais e propostas de solução emanadas dos profissionais que atuam no sistema. (MATÃO, 2003, p. 2-3) 
O PME de Matão está organizado nos seguintes tópicos: Justificativa; Caracterização Demográfica e Socioeconômica de Matão; Diagnóstico da Situação Educacional; Objetivos e Prioridades do PME; Prioridades e Estratégias de Atuação Específicas do Plano de Educação de Matão (Educação Infantil, Ensino Fundamental, Ensino Médio, Ensino Superior); Formação dos Recursos Humanos e Valorização Profissional; Gestão, Acompanhamento e Avaliação e; Análise dos Recursos Orçamentários e Financeiros.

A Justificativa do PME, além de mencionar os dispositivos legais pertinentes à sua elaboração, como, por exemplo, a Lei Federal 10.172 de janeiro de 2001, do Plano Nacional de Educação - PNE, estabelecendo a obrigatoriedade dos Estados, do Distrito Federal e dos Municípios elaborarem os respectivos planos decenais de educação, traz alguns apontamentos de que, em função do atraso na aprovação do antigo Plano Nacional de Educação - PNE - Lei no 10.172/01 (BRASIL, 2001) comprometeu, em parte, a elaboração do PME de Matão, especialmente em algumas situações decorrentes política educacional brasileira, expressas da seguinte forma:

Se o PNE tivesse sido aprovado para ter vigência a partir de janeiro de 1998, ou mesmo de 1999, já teria sido submetido a um processo de avaliação. Com isso, por exemplo, a grande polêmica gerada pela instituição do Fundef e, consequentemente, os impactos não planejados sobre os sistemas estaduais e municipais poderiam ter sido minimizados ou já estariam em curso as correções de deficiências e distorções. O processo de elaboração dos Planos Municipais da Educação ocorre, portanto, em um contexto em que a maioria dos municípios já sofreu os efeitos das políticas educacionais implantadas depois de 1996. Essa constatação não deve significar que a elaboração do PME se restrinja ao cumprimento das disposições legais e ao ajustamento formal das metas do Plano Nacional para o âmbito do município. Justamente porque houve descompasso entre a adoção de medidas de descentralização de responsabilidades e o planejamento das transformações dos sistemas municipais de educação, torna-se necessário que o PME seja um instrumento efetivo de diagnóstico da situação local e de racionalização da política educacional do município. (MATÃO, 2003, p. 5).

Nas questões relativas ao iten Caracterização Demográfica e Socioeconômica de Matão, o PME informava que Educação Infantil representava a maioria do atendimento público municipal na educação.

A educação infantil da Matão por meio de creches e pré-escolas é amplamente liderada pela oferta do poder público municipal. Segundo 
os dados do Censo Escolar de 2003, das 1.243 matrículas em creches, 1182 são em instituições públicas municipais. Além disso, a evolução apresentada nos últimos anos (não existem, no Censo Escolar, dados sobre creches, anteriores a 2000) revela que as matrículas no setor privado têm diminuído, apresentando uma taxa média anual negativa. O mesmo se dá com relação às matrículas na pré-escola. As unidades da rede pública municipal têm liderado largamente o número de matrículas com taxa de crescimento média no período de 1999 a 2003 de $3,8 \%$ ao ano. As pré-escolas privadas, no entanto, têm apresentado taxa média de crescimento negativa de $-1,7 \%$ no mesmo período. (MATÃO, 2003, p. 18).

Assim, esta situação demonstrou que a responsabilidade do município com a oferta dessa modalidade passa a ser maior ainda. Neste contexto, o diagnóstico da rede municipal de ensino, contido no PME de Matão, referente à Educação Infantil, mencionou que esta modalidade de ensino se encontrara presente em quase todos os bairros e distritos da cidade e, além da divisão dos grupos das unidades escolares analisadas e avaliadas, teve como dimensão primeira, a infraestrutura dos prédios escolares, onde deveriam ser avaliadas as instalações físicas e os equipamentos existentes nas escolas.

Já os itens Diagnóstico e Propostas para Infraestrutura da Educação Infantil descritos no PME de Matão apontaram problemas e necessidades reais de melhorias nos prédios escolares desta modalidade de ensino, ainda que modestas, demonstrando que a análise inicial da situação da Educação Infantil no município de Matão foi consideravelmente realista, com as seguintes observações:

\begin{abstract}
A maioria das unidades dedicadas á educação infantil, dispõe apenas do mínimo necessário para o atendimento das crianças. As principais demandas apresentadas dizem respeito a reformas e adequação das instalações e de ampliação em algumas unidades. As demandas de infraestrutura podem se consideradas como relativamente modestas, restringindo-se às carências básicas e emergenciais das unidades. Em termos gerais as Emeis estão em situação melhor do que as Creches. (MATÃO, 2003, p.32).
\end{abstract}

O diagnóstico de infraestrutura da Educação Infantil presente no PME de Matão, também demonstrou a necessidade de transcender as reformas para atendimento de demanda conjuntural, apontando a necessidade de expansão da rede e definição de um padrão de unidade escolar para a Educação Infantil de Matão, assim justificada: 
A existência de um padrão é importante para planejar as reformas e ampliações das unidades existentes, bem como as necessidades de construção de novas unidades, ou seja, quando a demanda da área de influência de uma unidade ultrapassa a sua capacidade de atendimento, torna conveniente expandir a rede com uma nova unidade. (MATÃO, 2003, p. 32).

Segundo o PME de Matão, a resolução de boa parte dos problemas relacionados à manutenção da infraestrutura existente, assim como para a ampliação da rede de escolas de Educação Infantil de Matão, passa, necessariamente, por uma maior integração das escolas com as comunidades em que estão inseridas. Posicionamentos dessa natureza, e com tamanha clareza, não são comuns, e foram assim expressos:

\begin{abstract}
O grande problema está na falta de retaguarda da rede para planejar, orçar e executar as adequações e reformas. Mesmo a manutenção dos prédios e instalações é bastante difícil. Nesse sentido, é de suma importância a concepção de um sistema de suporte para a infraestrutura da rede, que se articule com as associações da comunidade de pais, das diversas escolas. A eficácia desse sistema pode estar diretamente associada ao processo de mobilização da comunidade de cada escola. (MATÃO, 2003, p. 32) .
\end{abstract}

No período em que foi elaborado o PME de Matão, toda a demanda do Ensino Fundamental era atendida pela Secretaria de Educação do Estado de São Paulo (SEE/SP) e a demanda da Educação Infantil era praticamente atendida exclusivamente pelo município. Nesse sentido, a Secretaria Municipal de Educação de Matão, por meio do PME, procurou atender as demandas por ampliação e melhoria das condições de infraestrutura, definindo de critérios objetivos de dimensionamento das necessidades e de priorização no uso dos recursos.

Esses critérios procuraram dimensionar a capacidade instalada das unidades na perspectiva das instalações físicas e na capacidade de atendimento do pessoal contratado. Assim, em 2013, ainda havia, no município de Matão, problemas de atendimento à demanda potencial na medida em que um número significativo de unidades escolares apresentou lista de espera de matrículas, o que significa, na prática, que a demanda por vagas na Educação Infantil desse município estava maior que a oferta de vagas.

6 Tomé (2014) considera que esse aspecto, integração escola e comunidade, é por vezes bastante conturbado, pois enquanto a escola de Educação Infantil acredita que os pais só recorrem as creches porque não tem onde deixar seus filhos enquanto trabalham (o que é verdade), os pais, por sua vez, entendem que a Educação Infantil deve preparar seus filhos para o Ensino Fundamental e para o futuro (o que também é verdade). 


\section{CONSIDERAÇÕES FINAIS.}

Depois de analisar os dados fornecidos pela Secretaria Municipal de Educação de Matão e de comparar esses dados com as propostas contidas no Plano Municipal de Educação do município de Matão (2003-2013), podemos fazer algumas considerações, muito mais no sentido de utilizar a realidade desse município da região central do interior paulista como um exemplo do que, muito provavelmente ocorreu em uma quantidade significativamente grande dos municípios brasileiros, quer seja, uma demanda maior que a oferta de vagas na Educação Infantil, ainda que os respectivos sistemas municipais de educação apresentassem, como é o caso de Matão, escolas de Educação Infantil com uma boa infraestrutura física e material.

Especificamente no caso do município de Matão, podemos fazer duas constatações. A primeira é que as condições de infraestrutura física e material dos prédios de Educação Infantil da rede municipal de ensino de Matão, apresentaram melhorias e estão em condições ideais de atendimento (reformas, adequação e ampliação), exceto em alguns prédios, em que se apresentaram problemas quanto à acessibilidade, porém, por outro lado, também foi verificada a de construção de 04 prédios novos, onde esse problema da acessibilidade inexiste.

A segunda constatação é que, no que se refere à demanda, percebe-se que a rede municipal de ensino de Matão ainda apresenta problemas de atendimento, problemas esses objetivados pela existência de listas de espera para matrícula (vagas) na Educação Infantil, na maioria das unidades escolares, ainda que tenha ocorrido um aumento de quase $25 \%$ no número total de escolas de Educação Infantil na cidade de Matão no decênio 2003-2013.

Por fim, gostaríamos de ressaltar que essas constatações encontradas na realidade educacional no município de Matão, no nível da Educação Infantil, não diferem da realidade da maioria dos municípios brasileiros de médio e pequeno portes. Especificamente em relação ao problema da demanda maior que a oferta de vagas na Educação Infantil, a situação nas grandes cidades é pior ainda. Só para se ter uma ideia do tamanho (e da gravidade) desse problema, no que se refere às vagas em creches, a meta de atendimento proposta pelo novo Plano Nacional de Educação (PNE - Lei $\mathbf{n}^{\circ}$ 13.005/14) de, até 2024, atender, no mínimo 50\% do total de crianças brasileiras de 0 a 3 anos de idade é exatamente igual ao percentual proposto em 2001, portanto há mais de 13 anos, na primeira meta da Educação Infantil do antigo Plano Nacional de Educação - 
PNE - Lei $n^{\circ}$ 10.172/01 (BRASIL, 2001). Isso explicita o tamanho do desafio que temos pela frente.

THE EARLY CHILDHOOD EDUCATION AND THE MUNICIPAL PLAN OF EDUCATION OF MATÃO (SP): THE COMPLIANCE WITH DEMAND AND INFRASTRUCTURE

ABSTRACT: This article analyzes the compliance with demand and the infrastructure conditions of the buildings of child education of the municipal system of Matão (SP) and compares it with the proposed for this education level in some aspects (offer, services and infrastructure) present in Municipal Plan of Education of Matão (SMEs 2003-2013). Finally, this work makes some observations about the current situation of the Child Education System. Then, it concludes that the general problems about Child Education in Matão are the same problems presented in a great part of Brazilian cities, especially the problem about the demand - this is larger than the number of vacancies available in Child Education (specially in nursery school).

KEYWORDS: Child education. PME - Municipal Plan of Education. The compliance with demand. Infrastructure.

\section{REFERÊNCIAS}

ALGEBAILE, E. Escola pública e pobreza no Brasil. Rio de Janeiro: FAPERJ, 2009.

BRANDÃO, C. da F. Os desafios do novo Plano Nacional de Educação (PNE - Lei $\mathbf{n}^{0}$ 13.005/14): comentários sobre suas metas e suas estratégias. São Paulo: Avercamp, 2014.

BRANDÃO, C. da F. LDB passo a passo: lei de diretrizes e bases da educação nacional (Lei ${ }^{\circ}$ 9.394/96) comentada e interpretada, artigo por artigo. 4. ed. rev. e ampl. São Paulo: Avercamp, 2010.

BRANDÃO, C. da F. A educação infantil no Plano Nacional de Educação: a questão da oferta e do atendimento. In: PASCHOAL, J. D. (Org.). Trabalho pedagógico na educação infantil. Londrina: Humanidades, 2007. p. 77-86.

BRANDÃO, C. da F. PNE passo a passo (Lei no 10.172/2001): discussão dos objetivos e metas do Plano Nacional de Educação. São Paulo: Avercamp, 2006.

BRANDÃO, C. da F. Estrutura e funcionamento do ensino. São Paulo: Avercamp, 2004.

BRANDÃO, C. da F.; PASCHOAL, J. D. (Org.). Ensino fundamental de nove anos: teoria e prática na sala de aula. São Paulo: Avercamp, 2009.

BRASIL. Senado Federal. Constituição da República Federativa do Brasil. Brasília, 2006. 
Lei n. 10.172, de 9 de janeiro de 2001. Aprova o Plano Nacional de Educação e dá outras providências. Diário Oficial [da] União, Brasília, DF, 10 jan. 2001.

Disponível em: <http://www.planalto.gov.br/ccivil_03/leis/leis_2001/110172.htm>. Acesso em: 11 ago. 2013.

BOTO, C. A escola do homem novo: entre o iluminismo e a Revolução Francesa. São Paulo: Ed. da UNESP, 1996. (Série Enciclopaidéia).

CAMPOS, M. M.; FULLGRAF, J.; WIGGERS, V. A qualidade da educação infantil brasileira: alguns resultados de pesquisa. Cadernos de Pesquisa, São Paulo, v.36, n.127, abr. 2006, p. 87-128.

DOURADO, Luiz Fernandes. Políticas e gestão da educação básica no Brasil: limites e perspectivas. Educação \& Sociedade, Campinas (SP), v. 28, n. 100, out. 2007, p. 921946.

KRAMER, S.; NUNES, M. F. R.; CORSINO, P. Infância e crianças de 6 anos: desafios das transições na educação infantil e no ensino fundamental. Educação e Pesquisa, São Paulo, v. 37, n.1, p. 69-95, jan./abr. 2011.

MATÃO (SP). Lei n. 3.376, de 16 de dezembro de 2003. Institui o Plano Municipal de Educação de Matão. Leis Municipais, 16 dez. 2003. Disponível em:

$<$ https://leismunicipais.com.br/a/sp/m/matao/lei-ordinaria/2003/338/3376/lei-ordinarian-3376-2003-institui-o-plano-municipal-de-educacao-de-matao>. Acesso em: 11 ago. 2013.

TOMÉ, M. F. A educação infantil foi para a escola, e agora? introdução ao estudo da gestão escolar na educação infantil. Jundiaí: Paco, 2014.

TRINDADE, J. M. B. O abandono de crianças ou a negação do óbvio. Revista

Brasileira de História, São Paulo, v. 91, n. 37, p. 35-58, 1999. 